\title{
Linking quality management to manufacturing strategy: an empirical investigation of customer focus practices
}

\author{
Rui Sousa* \\ Faculdade de Economia e Gestão, Universidade Católica Portuguesa at Porto, Rua Diogo Botelho, 1327, 4169-005 Porto, Portugal
}

Keywords: Quality management; Customer focus; Manufacturing strategy; Contingency research

\begin{abstract}
Quality management (QM) has often been advocated as being universally applicable to organizations. This is in contrast with the manufacturing strategy contingency approach of operations management $(\mathrm{OM})$ which advocates internal and external consistency between manufacturing strategy choices. This article investigates, using the case-study method, whether customer focus practices-a distinctive subset of the whole set of QM practices-are contingent on a plant's manufacturing strategy context. The study strongly suggests that customer focus practices are contingent on a plant's manufacturing strategy and identifies mechanisms by which this takes place. The findings inform the implementation of QM programs.
\end{abstract}

\section{Introduction}

Quality management (QM) has become an allpervasive management philosophy having found its way into most countries and business sectors. Having been mostly led by practitioners, QM acquired a strong prescriptive stance in its initial diffusion stages (mainly the 1980s and early 1990s) with practices often being advocated as universally applicable to organizations. The emergence of awards such as the Malcolm Baldrige National Quality Award and the European Quality Award have reinforced the universal profile of QM practices at this time.

In the early 1990s, the initial enthusiasm over the universality of QM began to be tempered by numerous reports in the practitioner literature of problems in implementing QM (e.g. Harari, 1993; MacDonald,

\footnotetext{
* Tel.: +351-22-6196200; fax: +351-22-6196291.

E-mail address: rsousa@porto.ucp.pt (R. Sousa).
}

1993; Papa, 1993). The proponents of the universal view of QM would argue that these implementation difficulties are part of moving an organization towards quality, but an alternative explanation is that those difficulties result from too great a mismatch between the proposed form of QM and the particular organizational context. This explanation had been largely overlooked by the predominantly practitioner literature on QM implementation.

More recently, rigorous academic studies have started to question the universal validity of $\mathrm{QM}$ practices by addressing the influence of the organizational context on QM practice (Sousa and Voss, 2002). Of these, only a few studies directly and rigorously addressed this issue within an explicit contingency framework, all of them suggesting that the effectiveness of QM practices is contingent on the organizational context. Relevant contextual variables include managerial knowledge, corporate support for quality, external quality requirements and product 
complexity (Benson et al., 1991), organizational uncertainty (Sitkin et al., 1994; Reed et al., 1996), international competition (Das et al., 2000), manufacturing strategy context (Sousa, 2000; Sousa and Voss, 2001), firm size, capital intensity, degree of diversification, timing of QM implementation and maturity of QM program (Hendricks and Singhal, 2001). Other studies, whose main purpose was not to investigate QM contingencies, have tangentially uncovered other contextual factors affecting QM practices, such as industry (Maani, 1989; Powell, 1995), country (Madu et al., 1995), and product/process factors (e.g. manufacturing system, Maani, 1989; type of work an organization does, Lawler, 1994; breadth of product line and frequency of product changes, Kekre et al., 1995; work design, Victor et al., 2000). In addition, several large scale empirical studies examining the impact of QM on firm performance have found that some QM practices did not have a significant impact on performance (e.g. Powell, 1995; Dow et al., 1999; Samson and Terziovski, 1999), some of them suggesting that this may be due to these practices being context dependent (Powell, 1995; Dow et al., 1999). At a more general level, Dean and Bowen (1994) point out that the universal orientation of QM contrasts with the contingent approach of existing management theory.

The contingency perspective is not new in the operations management $(\mathrm{OM})$ field. In fact, $\mathrm{OM}$ has been strongly rooted from its inception on a manufacturing strategy contingency approach. The assumption of this approach is that internal and external consistency between manufacturing strategy choices increases performance (e.g. Woodward, 1965; Hayes and Wheelwright, 1979; Hill, 1985; Ward et al., 1996). Internal consistency refers to the coherence between the different elements of a manufacturing strategy; external consistency refers to the match between this set and the wider organizational context (e.g. marketing strategy). Many of the potential contingency factors uncovered in the QM contingency studies cited earlier have strong associations with the manufacturing strategy context. Despite the tensions identified in the literature-apparent across different streams of research in the QM field-there is still little empirical research directly addressing the question: are QM practices contingent on an organization's manufacturing strategy context?
In order to contribute to this need, this article concentrates on a critical and distinctive subset of the whole set of QM practices, customer focus practices. The importance of investigating the specific links between customer focus practices and manufacturing strategy is two-fold. First, customer focus is seen as the starting point of any quality initiative. Second, while the concept of customer focus has been heavily researched from a marketing perspective, it has not received the attention, it deserves in the OM field. As defined in the context of QM, customer focus practices involve the establishment of links between customer needs and satisfaction and internal processes. However, the emphasis of existing research in marketing has been on the identification and measurement of customer needs and satisfaction, having virtually left untouched the links between these needs and a plant's internal processes. An OM perspective can therefore effect significant contributions.

This article tries to fill this specific gap by investigating links between customer focus practices and manufacturing strategy by addressing two related research questions: (i) are customer focus QM practices contingent on a plant's manufacturing strategy context (analysing)? and (ii) if so, what are the mechanisms by which manufacturing strategy context affects those practices (explaining)? The study adds to the sparse empirical contingency work in QM mentioned earlier in that while most studies were geared towards hypotheses testing based on large survey samples (e.g. Benson et al., 1991; Das et al., 2000; Hendricks and Singhal, 2001), the study in hand is mainly theory-building based on case studies with the objective of not only uncovering contingency effects but also to produce empirically grounded explanations for them. Survey type studies lack this explaining ability. For example, Benson et al.'s (1991) landmark study found that only one product/process factor-product complexity-among several others of this type (e.g. rate of product/process change) affected QM. But no explanation could be derived of why only product complexity mattered and how this factor affected QM. Subsequently, other studies found evidence of the influence of product/process factors on QM practices (e.g. Sousa and Voss, 2001). Understanding the mechanisms by which context affects QM may contribute to reconciling such results and is also valuable to develop levers for proactive managerial action (e.g. 
how to overcome eventual obstacles posed by context on the use of QM practices).

The structure of the article is as follows. First, it describes the multiple case-study research design that was used to address the research questions. Second, the methodology of the study, including sample selection and data collection, is addressed. Next, it describes a first stage of analysis consisting of the reduction of case data on the several research variables in preparation for a second stage of deeper analysis. It then addresses the second stage of analysis directed at answering the research questions. This includes the analysis of the reduced case data for the uncovering of contingency effects and using the richness of the case data for the building of explanatory models linking manufacturing strategy context variables to customer focus practices. Finally, it presents the overall conclusions, limitations and suggestions for future research.

\section{Research design}

For the purposes of this study, a QM practice is considered to be contingent if its degree of use varies across different contexts. The adequacy of customer focus QM practices with respect to different manufacturing strategy contexts was inferred by observing the degree to which they were used in plants representative of different configurations of manufacturing strategy and which complied with certain research controls (these controls are described in detail in Section 2.1). Three main configurations have surfaced along time in several conceptual and empirical OM studies (e.g. Stobaugh and Telesio, 1983; Miller and Roth, 1994; Ward et al., 1996) and there has been substantial agreement among them on the characteristics of those configurations. Table 1 summarizes the main characteristics of the configurations. These three configurations are consistent with other established works (e.g. Hayes and Wheelwright, 1979; Hill, 1985) and are generally accepted in the OM field. More recently, Ward et al. (1996) have proposed, conceptually, a fourth configuration named "Lean Competitor" representative of a manufacturer achieving both differentiation and cost leadership based on manufacturing capabilities (thus eliminating trade-offs between the two competitive criteria). However, because to date there has not been sufficient empirical support for this

Table 1

Summary characteristics of the three major manufacturing strategy configurations

\begin{tabular}{|c|c|c|c|}
\hline $\begin{array}{l}\text { Manufacturing } \\
\text { strategy configuration }\end{array}$ & Dominant competitive strategy & $\begin{array}{l}\text { Dominant order-winners and } \\
\text { qualifiers }\end{array}$ & Manufacturing strategy context \\
\hline ND & $\begin{array}{l}\text { Offer of a specialized product } \\
\text { bundle. Pursuit of a narrow } \\
\text { segment defined by customer, } \\
\text { product, or technology; } \\
\text { Differentiation achieved by } \\
\text { customization }\end{array}$ & $\begin{array}{l}\text { Order-winners: delivery speed } \\
\text { and/or unique design capability } \\
\text { (ability to make changes in } \\
\text { design and to introduce products } \\
\text { quickly; design quality). } \\
\text { Qualifiers: price, conformance } \\
\text { quality, on-time delivery. }\end{array}$ & $\begin{array}{l}\text { Low volume, high } \\
\text { customization, high variety, high } \\
\text { rate of new product introduction, } \\
\text { jobbing type manufacturing } \\
\text { processes, short run sizes. }\end{array}$ \\
\hline BD & $\begin{array}{l}\text { Provision of a wide range of } \\
\text { products to a variety of markets, } \\
\text { while striving to develop and } \\
\text { maintain a large share in each } \\
\text { market on the basis of quality } \\
\text { as opposed to price; use of new } \\
\text { product development in existing } \\
\text { markets as a means of } \\
\text { expanding market share and } \\
\text { preempting competitors. }\end{array}$ & $\begin{array}{l}\text { Order-winners: decreasing } \\
\text { importance of delivery speed } \\
\text { and unique design capability; } \\
\text { increasing importance of price. } \\
\text { Qualifiers: conformance quality, } \\
\text { on-time delivery. }\end{array}$ & $\begin{array}{l}\uparrow \\
\downarrow\end{array}$ \\
\hline CL & $\begin{array}{l}\text { Provision of final product bundle } \\
\text { at a lower price than comparable } \\
\text { offerings by competitors; focus } \\
\text { on a range of high-volume, } \\
\text { stable, usually mature products. }\end{array}$ & $\begin{array}{l}\text { Order-winners: price. Qualifiers: } \\
\text { design quality, conformance } \\
\text { quality, on-time delivery. }\end{array}$ & $\begin{array}{l}\text { High volume, low } \\
\text { customization, low variety, low } \\
\text { rate of new product introduction, } \\
\text { line type manufacturing } \\
\text { processes, long run sizes. }\end{array}$ \\
\hline
\end{tabular}


fourth configuration and there is still heated debate in the field between defenders of the lean production and the trade-offs perspectives, the lean competitor configuration was not considered in the study. The study employs Ward et al.'s (1996) terminology for the three configurations that were considered: niche differentiator (ND), broad differentiator (BD) and cost leader (CL).

The study employed the case method for several reasons. First, it is a recommended method when contextual conditions are pertinent to the phenomenon of study and when the research question embodies an explanatory, theory-building component (how does manufacturing strategy context affect customer focus practices?) (Yin, 1994). Qualitative data are particularly useful for understanding why or why not emergent relationships hold. When a relationship is supported, the qualitative data often provide a good understanding of the dynamics underlying the relationship, that is, the "why" of what is happening, which is crucial for the establishment of internal validity (Eisenhardt, 1989). Second, resulting from the adopted research design, there are three main groups of research variables: control variables, manufacturing strategy context variables, and the degree of use of customer focus practices. These variables are complex to measure, requiring close methods such as interviews, direct observation, and collection of archival data. In addition, the large number of variables to address pose obstacles to the use of distant methods, such as postal surveys. Finally, it would be extremely difficult to obtain the tightly controlled sample required for the study (see research controls in Section 2.1) using a large sample survey design, both because of the small size of the pool of eligible plants and the difficulty in assessing the plants' compliance with the established research controls via such distant methods. In fact, the five cases that make up the study's sample were clinically chosen so that they exhibited optimal characteristics for the propositions to be examined (see Sections 2.1 and 3.1).

The following sections address the three main groups of research variables in the study.

\section{Research controls}

In order to isolate the effects of the manufacturing strategy context on the degree of use of QM practices from other potentially confounding factors, the study examined plants complying with the following research controls (Section 3.1 describes how the research sample was selected).

(1) There is a high level of awareness of the whole range of customer focus practices encapsulated under the QM theme. All plants were involved in best practice benchmarking exercises, had been ISO 9000 certified for at least 7 years (going through the ISO 9000 certification process increases quality awareness (e.g. Corrigan, 1994)) and were members of quality associations.

(2) The plants are "quality mature" in terms of having had a formal program of quality improvement in place for an extended period of time and having successfully implemented QM practices. The duration of the formal QM programs ranged from 7 to 20 years (a 3-year period is generally considered to be the cut off point between young and mature organizations in QM (e.g. Ahire, 1996; Dale and Lascelles, 1997)) and there were external indicators of successful QM implementation for all plants, including the winning of reputable quality awards and having been the object of academic case studies illustrating best practice in QM.

It can be argued that such plants are likely to exhibit a pattern of use of practices adequate to their context. On the one hand, plants which are aware of the whole range of existing practices are more likely to have made an informed decision regarding the practices that were adopted (control number 1). On the other hand, with sufficient time elapsed since the adoption of a particular practice (control number 2), plants are better able to make a sound cost-benefit assessment of that practice's use: either the adoption of the practice bears fruits and the practice is likely to be maintained in use; or its inadequateness is acknowledged and the practice is likely to be discarded. The long-term pattern of use of practices is assumed to be determined by the interaction of the ideal (or espoused) final form of best practice and the organizational context by means of cost-benefit mechanisms. Because the ideal form is shared widely by organizations-by virtue of its diffusion by the media, consultants, etc. and the organizations' strong quality awareness-the assumption that it is context that will determine the actual final form seems reasonable. 
Table 2

Definition of manufacturing strategy context variables

Degree of product customization

Production volume

Rate of new product introduction

Process typology

Internal item variety

Internal run sizes
The extent to which basic physical product characteristics are not known a priori due to being determined or influenced by the customer.

The total annual production volume in units in the plant's processes.

The frequency of introduction of new products and the occurrence of changes in product designs. The emphasis is on the consequences of these events to manufacturing.

The OM type of the production process: jobbing/low volume batch, high volume batch, line. The diversity of items dealt with by the production process (both in total number of different items and in the relative differences between them, as "experienced" by the process).

The size of the production runs as "experienced" by the production processes (i.e. many short batches of very similar products, requiring very quick or no set-ups, would be considered a single long run).
The data collected in the field supported this assumption. The plants had arrived at the current pattern of use of practices via a process of experimentation consisting in the adoption of new practices, the improvement of existing practices, and the discarding of unsuccessful practices. Plants were using certain practices because those practices had produced positive results for them over an extended period of time.

The research and sample designs were purposefully chosen so as to make it unnecessary to employ measures of the effectiveness of the several customer focus practices as indicators of contingency effects. Indeed, the use of such measures in a small sample study is fraught with difficulties. For example, because of the many confounding factors affecting performance (e.g. Hackman and Wageman, 1995, p. 320), it is meaningless to compare performance measures within a small sample: only a large sample would be likely to reveal any statistically significant effects. In addition, the objective of the study was mainly theory-building, i.e. to uncover eventual contingency effects and find empirically grounded explanations for them. As such, a substantial testing of these effects with the inclusion of performance issues is left for later stages of research, which, indeed, will benefit from the theory-building output of a study such as this.

\section{Manufacturing strategy context}

The research design involves selecting plants representative of different manufacturing strategy contexts. The classification of plants across the manufacturing strategy spectrum was based on the following contextual variables: degree of product customization, production volume, rate of new product introduction, process typology, internal item variety, and internal run sizes. Table 2 defines these variables. These dimensions are the most common ones in the literature on manufacturing strategy configurations (e.g. Hayes and Wheelwright, 1979; Stobaugh and Telesio, 1983; Hill, 1985; Miller and Roth, 1994; Ward et al., 1996).

\section{Customer focus QM practices}

Customer focus practices involve the establishment of links between customer needs and satisfaction and internal processes. The practices are categorized as in Table 3 which is consistent with several instruments which were developed to measure the key QM practice dimensions (e.g. Flynn et al., 1995; Ahire et al., 1996).

\section{Methodology}

\section{Sample selection}

In order to isolate the effects of manufacturing strategy context from other potentially confounding factors, the plants were all selected from the electronics industry, which is defined for the purposes of this study as manufacturers of products in which the core is one or several printed circuit boards (PCBs). The electronics industry was chosen because being a highly competitive industry in which QM has been strongly disseminated it increased the likelihood of finding plants complying with the established research controls.

The study used an intricate sample design (Harrigan, 1983) where the sample is selected to 
Table 3

Customer focus quality management practices

Customer relationships

Customer involvement in new product design/introduction

Collection of information on customer needs

Dissemination of information collected on customer needs within the organization and responsiveness to that information
Establishing strong relationships with customers by emphasizing partnership arrangements, direct customer contacts (face to face meetings, plant visits) and integration of the plant's operations with customers (logistics co-operation, single sourcing arrangements, mutual technical assistance, organization of the plant's activities around customers) The involvement of customers in the new product design/introduction process

The collection of information on customer needs via frequent and close interaction with customers, including forward looking information (for example, about new requirements, services or technologies needed by existing and potential customers), information on the importance placed by existing customers on several requirements (e.g. price, delivery), etc. The existence of mechanisms within the organization to disseminate and respond to information on customer needs coincide with sites that possess observable traits that are key factors in the propositions to be examined. As such, the target sample comprised two plants representing the ND configuration, two plants representing the $\mathrm{CL}$ configuration and one plant representing the BD configuration, all complying with the established research controls. Having two instances of each of the polar manufacturing strategy contexts allows for literal replication, i.e. to verify whether similar results occur for plants representative of the same context (Yin, 1994, p. 46). The single BD plant essentially acted as a bridge between the two polar contexts. Having instances representing all three contexts allows for theoretical replication, i.e. to verify whether contrasting results occur across contexts (Yin, 1994, p. 46). The total number of cases chosen (five) is in line with Eisenhardt's (1989) guideline that a number between four and ten usually works well.

The process for selecting individual plants was, first, to use publicly available information to select plants that appeared likely to match the required target sample criteria, then to test this initial judgment by collecting data in the field. This process was repeated until the target sample was achieved. Overall, 13 plants were contacted ( 4 in the ND category, 4 in the $\mathrm{BD}$, and 5 in the CL), 6 of which agreed to participate in the study ( $3 \mathrm{NDs}, 1 \mathrm{BD}$, and $2 \mathrm{CLs}$ ). Of these six plants, one ND plant was dropped for being found not to comply with the research controls after two-field visits. The way in which the manufacturing strategy configuration of the plants was classified is described in Section 4.2. Table 4 describes the final research sample.

\section{.Data collection}

Data collection focused on the formal research variables complemented with other issues enabling the understanding of the observed pattern of use of practices such as the history of use of the practices, the difficulties experienced by the plants in using them, and the factors which prevented plants from increasing or decreasing the use of some practices. Following the developed case-study protocol, several data collection methods were used including semi-structured interviews, direct observation (e.g. plant tours), a short questionnaire collecting descriptive plant data, and secondary data. A pilot case-study was conducted at plant 1 (chosen due to privileged access to the site) to refine the data collection plans with respect to both the content of the data and the field procedures to be followed.

Each plant was the object of a case-study involving four visits to the manufacturing site on separate days. Across cases, informants included the managing director, the plant manager, shop floor supervisors and workers, and representatives from marketing/sales, customer service, engineering, manufacturing, quality, testing, and product design/introduction. Interviews were typically $1 \mathrm{~h}$ long, having ranged across cases from $30 \mathrm{~min}$ to $4 \mathrm{~h}$. 
Table 4

Research sample

\begin{tabular}{|c|c|c|c|c|c|}
\hline & \multicolumn{5}{|l|}{ Plant } \\
\hline & 1 & 2 & 3 & $4^{\mathrm{a}}$ & $5^{\mathrm{a}}$ \\
\hline Revenue (US\$ in million) & 40 & 18 & 97 & 24 & 26 \\
\hline Employees & 450 & 123 & 226 & 170 & 224 \\
\hline Main products & $\begin{array}{l}\text { Electricity and gas meters } \\
\text { (commodity products) }\end{array}$ & $\begin{array}{l}\text { Access control systems for } \\
\text { buildings (hardware } \\
+ \text { architectural software } \\
\text { application) }\end{array}$ & $\begin{array}{l}\text { PCBs for assembly into final products } \\
\text { (document processing machines) at the } \\
\text { customers' plants. }\end{array}$ & $\begin{array}{l}\text { PCBs, standalone for assembly } \\
\text { into final product units by the } \\
\text { customer or already } \\
\text { incorporated into final product } \\
\text { units, in the context of the } \\
\text { provision of a manufacturing } \\
\text { service (subcontracting). }\end{array}$ & \\
\hline Customers & Electricity and gas utilities & $\begin{array}{l}\text { Dealers, selling products to } \\
\text { hospitals, police forces, etc. }\end{array}$ & $\begin{array}{l}\text { Plants part of the corporation to which } \\
\text { plant } 3 \text { belongs. PCBs supplied on a } \\
\text { free market basis }\end{array}$ & $\begin{array}{l}\text { Companies in the industrial, } \\
\text { instrumentation and } \\
\text { communication segments. }\end{array}$ & \\
\hline Nature of customization ${ }^{b}$ & $\begin{array}{l}\text { Own set of standard } \\
\text { products (OEM). }\end{array}$ & $\begin{array}{l}\text { Own set of standard products } \\
(\mathrm{OEM}) \text {. }\end{array}$ & $\begin{array}{l}\text { Production of PCBs to customer } \\
\text { supplied conceptual designs. Physical } \\
\text { design developed by the plant alone or } \\
\text { in tight co-operation with customer } \\
\text { (supplier/OEM). }\end{array}$ & $\begin{array}{l}\text { Production of PCBs to } \\
\text { customer supplied physical } \\
\text { designs. Customers also } \\
\text { influence testing strategies } \\
\text { (supplier). }\end{array}$ & \\
\hline
\end{tabular}

\footnotetext{
${ }^{a}$ Although plants 4 and 5 have similar profiles, there is no connection between them.
}

${ }^{\mathrm{b}}$ A conceptual design is a specification of the functions a PCB should perform (a circuit schematic). A physical design is the translation of a conceptual design into a physical layout of components and conductive tracks making up the physical PCB embodying the functional specifications. 


\section{Datareduction}

\section{General methodology}

Data reduction consisted mainly of the characterization of individual plants across the three sets of research variables (research controls, context variables, and degree of use of customer focus practices) so that conclusions could be drawn and verified in later and deeper stages of analysis. It comprised two main stages: (i) the organization and coding of the data that appeared in written-up field notes; and (ii) the characterization of plants across the several research variables. Stage (i) followed the usual guidelines for qualitative research (e.g. Miles and Huberman, 1994). Stage (ii) used the outcome of stage (i) to construct tabular displays to manage and present qualitative data across the relevant research variables, an analysis strategy recommended by Miles and Huberman (1994). These displays used a fixed set of items to characterize each variable, thus ensuring consistent and objective comparisons across the several cases, and were used to make "judgments" on the variables in question (e.g. whether a plant complied with a particular research control). In the process of building the displays several items of information related to a plant were given high, medium or low ratings. The rules that were used in arriving at these ratings were the following.

Rule 1: Rule for arriving at high, medium, low ratings for individual information items.

R1.1 Quantitative items (numerical values): The interval (minimum observed numerical value across plants; maximum observed numerical value across plants) was divided into three equally sized intervals, each corresponding to the low, medium, and high ratings.

R1.2 Qualitative items (textual descriptions): The plants were ranked according to the item in question with the level high being attributed to the plant ranked the highest and the level low to the plant ranked the lowest. A notional item was considered in between these two extremes as an exemplar of the medium rating. These three items (two real and one notional) then acted as the anchor points for the rating of the remaining plants. The remaining plants were attributed the rating high, medium and low according to the anchor item they most resembled. This procedure is equivalent to the one followed for the quantitative items.
Rule 2 (R2): Rule for arriving at a high, medium, low rating for an aggregate variable made up of several individual items (dimensions), each rated as high, medium or low. The ratings of high, medium and low corresponding to the individual items making up the aggregate variable for a plant were assigned the values 3,2 , and 1 respectively. These values were added to arrive at a numerical score for the variable. This score was compared with the other plants' scores to arrive at a high, medium, low rating using rule R1.1.

The fact that the ratings are relative to other plants, thus independent of the researcher's realm of experience and the fact that the study controls for industry allowed for simple comparisons of like with like.

The characterization of the plants in terms of the established research controls was already discussed in Section 2.1. The specific displays used for the other research variables and the individual items which were used to measure/characterize those variables are discussed in the following sections.

\section{Classifying the manufacturing strategy configuration of plants}

A data display comprising all the contextual variables was constructed for each plant. Appendix A shows the template that was used. The three manufacturing strategy configurations that are considered in this study are representative, but not exhaustive of the entire realm of strategic possibilities. As such, the plants in the study were classified according to their degree of similarity to one of the representative configurations, even though not all the contextual variables might match that ideal configuration. Table 5 shows the ratings of the contextual variables across plants and the subsequent classification of the plants.

\section{Rating the degree of use of customer focus QM practices}

The customer focus practices were characterized for each plant using a data display. Each display comprised three columns: (i) a column containing a detailed, rich description of the use of the practices in the plant in question (showing the evidence of their use as defined in Table 3); (ii) a column summarizing the previous information across relevant dimensions; (iii) a final column rating the degree of use of practices 
Table 5

Classification of the manufacturing strategy configurations of the plants in the research sample

\begin{tabular}{lllllc}
\hline & Plant & & & \\
\cline { 2 - 5 } & 1 & 2 & 3 & 3 & 5 \\
\hline Product Customization & 1 & 1 & 2 & 3 & 3 \\
Production volume & 1 & 3 & 1 & 2 & 3 \\
Rate of NPI & 1 & 1 & 2 & 3 & 3 \\
Internal item variety & 1 & 1 & 2 & 3 & 3 \\
Internal run sizes & 1 & 1 & 2 (Batch) & 3 \\
Dominant process typology & 1 (Line) & 1 (Line) & 11 & 17 & 3 (Jobbing) \\
Total plant score & 6 & 8 & BD & ND & ND \\
Plant classification & $\mathrm{CL}$ & $\mathrm{CL}$ & & \\
\hline
\end{tabular}

Closest similarity to the cost leader (CL), broad differentiator (BD), and niche differentiator (ND) configurations are denoted by 1 (high),

2 (medium) and 3 (low) denote, respectively. Plants were classified applying rule R1.1 to the total plant scores.

as high, medium or low, by applying rule R1.2 to the previous column.

\section{Data analysis}

This section describes how the data were analyzed to answer the two research questions: (i) are customer focus QM practices contingent on a plant's manufacturing strategy context (analyzing)? and (ii) if so, what are the mechanisms by which manufacturing strategy context affects those practices (explaining)? The several analyses that were performed are presented first and then discussed jointly at the end.
Analyzing the association between overall manufacturing strategy context and the pattern of use of practices

Table 6 summarizes the degree of use of the several customer focus practices across plants resulting from the data reduction stage. The plants are ordered according to their relative positions along the manufacturing strategy context spectrum as given by the context scores in Table 5.

The visual pattern in Table 6 suggests that customer focus practices are contingent on manufacturing strategy context. To investigate this hypothesis, two complementary statistical analyses were conducted.

Table 6

Degree of use of customer focus QM practices across plants

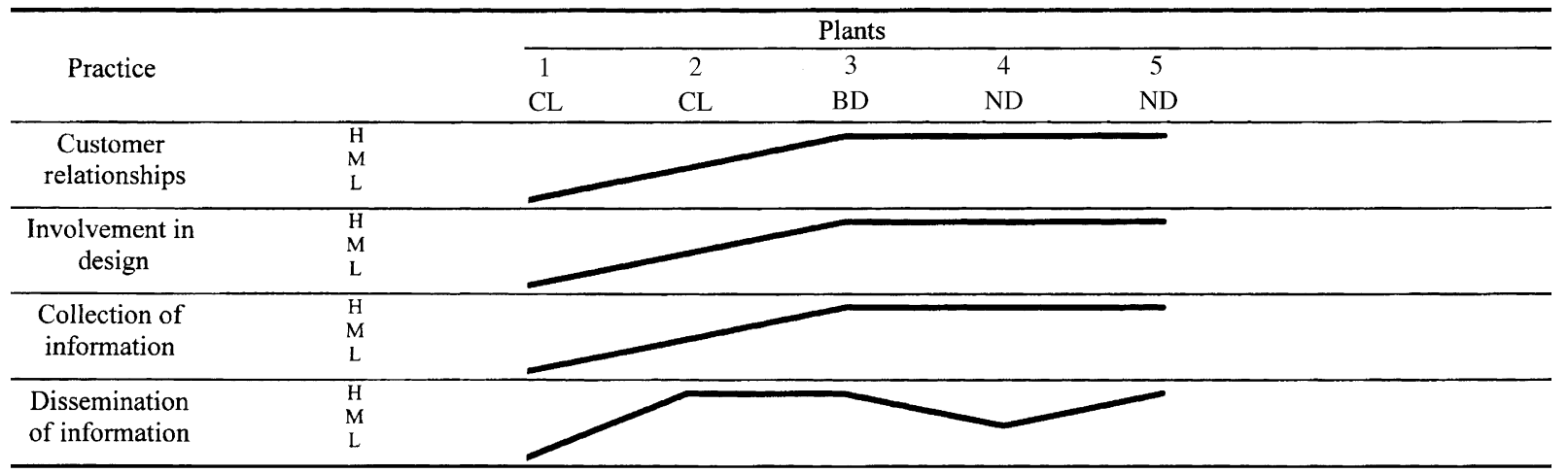

H: high; M: medium; L: low. 
Because of the small sample size $(n=5)$ nonparametric methods based on the ranks of the degree of use of practices were used. The use of ranks has the additional advantage of making the results robust to individual variable ratings because these can be subjected to reasonable changes without affecting the ranks of the variables. The first piece of analysis tested whether a relative movement across the manufacturing strategy spectrum was significantly associated with a relative change in the degree of use of practices, considering plants individually rather than grouped by manufacturing strategy configuration. To this effect, the Spearman's rank correlation coefficient (e.g. Conover, 1999) between a context variable (CTX) categorizing the relative position of each plant across the manufacturing strategy spectrum as given by Table 5 (CTX takes the value 1-5 for plants $1-5$, respectively) and the degree of use of each practice across the plants as given by Table 6 (3 (high), 2 (medium) or 1 (low)) was computed. CTX was found to be significantly (0.05 level) and strongly (correlation coefficient: 0.89 ) correlated with the degree of use of all practices, except for dissemination of information. This suggests that changes in overall manufacturing strategy context significantly explain a large part of the variability in the degree of use of individual practices.

The second piece of analysis applied Cuzick's (1985) nonparametric test for trend to the degree of use of individual practices across the plants now grouped in three manufacturing strategy configurations assumed to be equally spaced along the manufacturing strategy spectrum. Thus, for each practice, the two polar groups comprised two observations each and the BD group comprised a single observation. All practice trends were found to be significant at the 0.10 level, except for dissemination of information. Given the small sample size and the non-parametric nature of the test (which reduce its statistical power), a 0.10 significance level may be considered as adequate evidence of trend. However, the reduced significance level may indicate the presence of other important variables at play besides manufacturing strategy context. In fact, Table 6 shows a misalignment between the three manufacturing strategy configurations and the pattern of use of practices: the two CL plants exhibit reasonably different patterns between them, while the BD plant exhibits a pattern which is similar in the main to the two ND plants. Taken together, the two statistical analyses suggest that manufacturing strategy context plays a significant role, simultaneously raising the possibility of other important variables being also at play in determining the pattern of use of practices.

\section{Explaining the pattern of use of practices}

In this analysis, the richness of the case data was used to investigate in greater depth the patterns uncovered in the statistical analyses. In this process, a theory-building mode was adopted to identify the mechanisms by which manufacturing strategy context influenced the use of customer focus practices, thereby producing explanations for the empirical observations. The analysis consisted of building causal networks, an analysis strategy recommended for explanation (Miles and Huberman, 1994). A causal network is a "display of the most important independent and dependent variables in a field study and of the relationships among them" (Miles and Huberman, 1994, p. 153).

Five networks - one for each case-were built following Miles and Huberman's (1994) guidelines. The working blocks were the codes, researcher comments, interim case summaries and the displays constructed in the data reduction stages. In the whole process, several tactics for generating meaning were used such as noting patterns, seeing plausibility, clustering, counting, making contrasts/comparisons, subsuming particulars into the general, noting relations between variables, finding intervening variables and building a logical chain of evidence (Miles and Huberman, 1994, pp. 245-262). As more knowledge became available during the course of the field work and associated conceptualization, recurrent patterns of interaction between variables within the orienting research framework started to emerge, both within and across cases. Some variables looked connected, while others looked random or unconnected. These patterns guided guesses about directions of influence among sets of variables. Initial versions of the causal networks were amended and refined as they were successively tested against the data collected in the field. During this process, negative evidence opposing the emerging relationships as well as rival explanations were actively looked for. In addition, feedback was received from informants on the networks' emerging relationships. This process led to five individual 
networks whose relationships received support from the data.

\section{Cross-case analysis}

The five individual case networks were compared with each other in order to identify similarities and differences. These comparisons resulted in the extraction of relationships that were found to replicate across cases, abstracting from the peculiarities of individual cases and generalizing them to a broader theory. During this process, it emerged that the pattern of use of customer focus practices was best explained by the influence of two main contextual factors characterizing the way in which a plant differentiated its overall service offering.

(i) Degree of service differentiation: The extent to which a plant is able to differentiate its overall service offering by providing services associated with the physical product items that it manufactures, such as the design/configuration of the products, associated software, or after sales support. This characteristic is not based on manufacturing.

(ii) Degree of product customization: The extent to which a plant is able to differentiate its overall service offering by physically customizing product items.
The variable "degree of product customization" is very commonly considered in the manufacturing strategy literature. Indeed, it has been used in this study to classify a plant's manufacturing strategy context (refer to Table 2). On the other hand, because it is not manufacturing related, the variable "degree of service differentiation" is not usually considered in the manufacturing strategy field. Consistent with this, in this study, the variable was not originally considered in the classification of a plant's manufacturing strategy context. However, because the case-study evidence identified it as important for customer focus practices, it was considered as a research variable a posteriori, a procedure frequently used in theory-building case-study research (Eisenhardt, 1989).

During the cross-case analysis, it was found that the directions of the effects of product customization and service differentiation were similar in the two ND and the BD plants among them, and in clear opposition to the directions in the CL plant 1 . The CL plant 2 differed significantly from plant 1 in this respect and exhibited a transition pattern between the two polar groups. This resulted in the grouping of plants in three configurations of "service offering" as shown in Table 7.

Based on the five individual causal networks, two general (cross-case) causal networks were built for the

Table 7

The three configurations of service offering

\begin{tabular}{|c|c|c|c|}
\hline \multirow{2}{*}{$\begin{array}{l}\text { Service offering } \\
\text { configuration }\end{array}$} & \multirow[t]{2}{*}{ Plants } & \multicolumn{2}{|c|}{ Characterization in terms of the two key context variables } \\
\hline & & Service differentiation $^{\mathrm{a}}$ & Product customization \\
\hline Manufacturing service & $\begin{array}{l}\text { ND plants } 4 \text { and } 5 \text {; } \\
\text { BD plant } 3\end{array}$ & $\begin{array}{l}\text { High: complexity of the } \\
\text { manufacturing service allows for } \\
\text { wide differentiation based on design } \\
\text { and service aspects. }\end{array}$ & $\begin{array}{l}\text { High/medium: production to } \\
\text { customer supplied designs }\end{array}$ \\
\hline $\begin{array}{l}\text { Physical product and } \\
\text { architecture/service }\end{array}$ & CL plant 2 & $\begin{array}{l}\text { Medium: offering standard physical } \\
\text { products configured in customized } \\
\text { architectures with associated software } \\
\text { allows, in the target markets, for } \\
\text { substantial differentiation in terms of } \\
\text { architectural design and after sales } \\
\text { service. }\end{array}$ & $\begin{array}{l}\text { Low: own set of standard physical } \\
\text { product items }\end{array}$ \\
\hline Commodity product & CL plant 1 & $\begin{array}{l}\text { Low: markets perceive products as } \\
\text { commodities, hence are not receptive } \\
\text { to differentiation attempts at the } \\
\text { expense of price. Virtually no service } \\
\text { associated with product. }\end{array}$ & $\begin{array}{l}\text { Low: own set of standard physical } \\
\text { product items }\end{array}$ \\
\hline
\end{tabular}

a The high, medium and low ratings were obtained by applying the data reduction rule R1.2 to the plants' context data. 


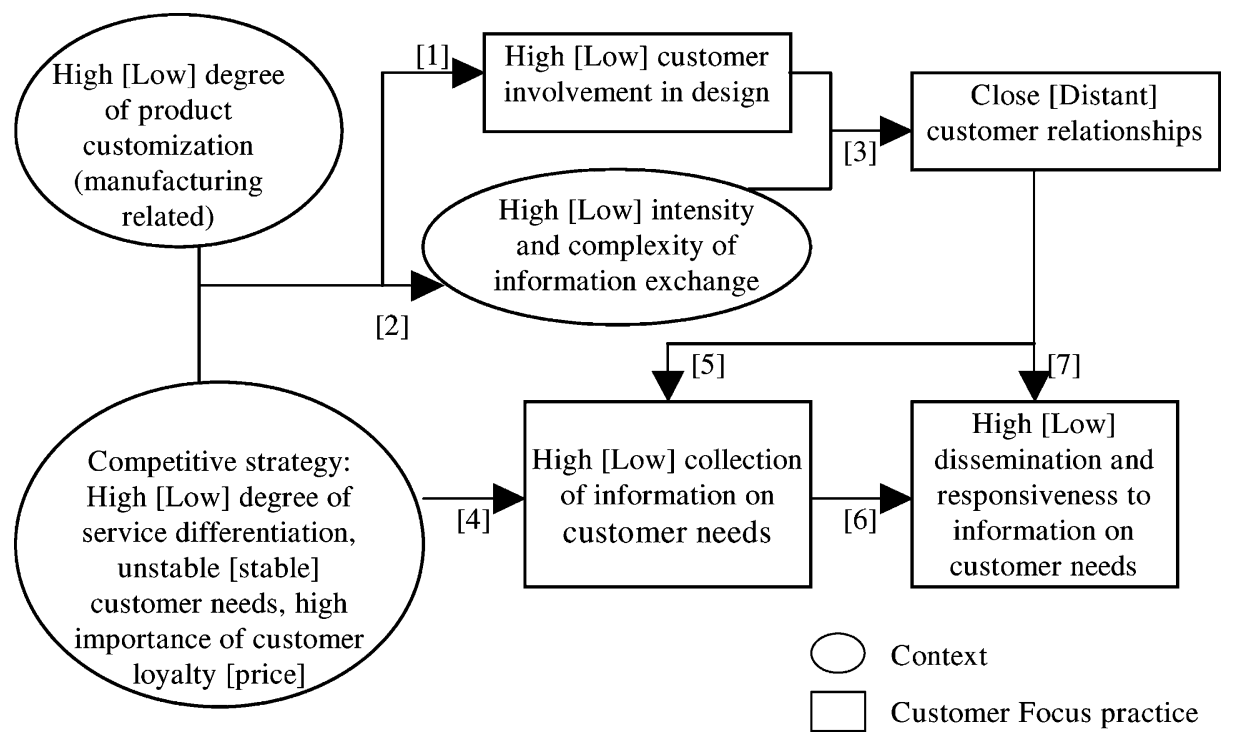

Fig. 1. Causal networks for the use of customer focus practices in a manufacturing service and commodity product service offering configurations (commodity product labels are in square brackets).

two polar groups of plants, embodying generalizable explanations that were grounded in the five individual case networks. Fig. 1 condenses the two general networks. The research variables are shown in boxes or circles and the relationships among them are shown by arrows. The meaning of the connections among variables in the two networks is next described by taking the manufacturing service configuration as the basis of the description and adding the necessary comments regarding the commodity product configuration in square brackets.

\section{Customer focus for aprovider of amanufacturing service [commodity product]}

A high degree of product customization (namely the production to a customer supplied design) and service differentiation (namely the provision of a manufacturing service) dictate a strong customer involvement in product design in order to clarify designs and discuss manufacturibility and other manufacturing related issues (e.g. testing strategies) (relationship 1). This also requires intensive and complex exchange of information with customers to determine all the parameters of the product and service offering (relationship 2). The high involvement in design and the need for intensive and complex information exchange lead to close customer relationships (relationship 3). For example, several of the plant's activities may be organized around customers (e.g. customer focused cells), and there may be frequent and systematic contacts with customers via a rich medium (e.g. personal contacts, video conference links). [In contrast, for the provider of a commodity product, the low degree of customization and service differentiation do not demand a strong customer involvement in product design (relationship 1) and make price the main parameter defining the service offering. This leads to a low intensity and low complexity exchange of information with customers (relationship 2) which may be limited to demonstrating product conformance quality. The low involvement of customers in design and the low level of information exchange do not lead to close customer relationships, with the plant's activities being mostly isolated from the direct influence of customers (relationship 3).]

The high degree of service differentiation and the uncertainty concerning customer needs mean that the benefits from collecting information on customer needs are high (relationship 4). A good knowledge of customer needs also increases customer loyalty and repeat business which are very important competitive priorities under the chosen competitive strategy. Collecting information on customer needs is in turn 
facilitated by the plant's close relationships with customers (relationship 5). The good availability of information on customer needs (relationship 6) and the fact that several of the plant's activities are organized around customers (relationship 7) require strong mechanisms for disseminating and responding to this information. These include strong links to the manufacturing function which is heavily influenced by customers. [The exact reverse arguments explain the pattern of use of practices in the provider of a commodity product.]

\section{Discussion}

The statistical analyses suggested that the pattern of use of customer focus practices was strongly influenced by a plant's overall manufacturing strategy context although it revealed that there might be other important variables also at play. The causal network analyses reinforced this conclusion. For every plant, they uncovered mechanisms by which two key characteristics (more than the manufacturing strategy context characteristics overall) determined the observed pattern of use of practices: the degree of product customization and the degree of service differentiation. While degree of product customization is perfectly aligned with overall manufacturing strategy context configurations (that is, there is a one-to-one correspondence between the variable ratings and the manufacturing strategy configurations of the plantssee Table 5), the degree of service configuration is not (see Table 7). This explains the misalignment between the manufacturing strategy configurations of the plants and the patterns of use of practices that was observed in Section 5.1. This has led to the grouping of plants into three service offering configurations which do not exactly match the three manufacturing strategy configurations: manufacturing service, comprising the ND and BD plants; physical product and architecture/service, comprising the CL plant 2; and commodity product, comprising the CL plant 1 . The fact that the CL plants 1 and 2 are different in terms of the degree of service differentiation deserves a comment in connection with Ward et al.'s (1996) fourth proposed manufacturing strategy configuration of lean competitor. As can be seen in Table 7, the differences between the plants arise from differences in their markets. Therefore, although plant 2 combines low cost and differentiation elements, it does not fall under the lean competitor configuration because it does not achieve differentiation via manufacturing related capabilities. In fact, the two plants are very similar in terms of their manufacturing strategies (both providing low cost standard physical product items) and hence their joint classification as CLs.

The mechanisms by which product customization and service differentiation exerted their influence found literal replication (i.e. their application to contexts which were similar in respect to these two characteristics explained the similarity observed in the patterns of use of practices) and theoretical replication (their application to different contexts explained the differences observed in the patterns of use of practices). The causal network analyses also identified several interaction effects between customer focus practices (relationships 3, 5, 6 and 7 in Fig. 1), suggesting the existence of an internally coherent customer focus practice configuration matching a plant's context.

\section{Conclusions}

This study makes a contribution to the understanding of the influence of manufacturing strategy context on customer focus QM practices. It strongly suggests that customer focus practices are contingent on a plant's manufacturing strategy and identifies mechanisms by which this takes place. The study also highlights the importance of the interactions between individual practices, forming an internally coherent customer focus practice configuration matching a plant's context. This research offers a strong OM perspective on customer focus, bridging the gap between marketing (which has focused mainly on the identification of customer needs) and OM by providing insights on the links between customer needs and a plant's manufacturing strategy context. Content wise, the study's findings are not entirely surprising. However, many of the areas of manufacturing strategy that have been accepted for many years have had very little good research done to confirm the accepted relationships and gain deeper knowledge about them. In addition, examples abound in the field of OM of prescriptive and universalistic statements being made about the universal validity of many of its best practices, prominently among which are QM practices, and in particular, 
customer focus practices. This study contributes to tempering these statements, forging links between best practice and manufacturing strategy within a contingency framework. The identification of the specific mechanisms by which manufacturing strategy context impacts on customer focus also provides managers with important levers for action (see later).

The results of this study can be used to inform the implementation of QM programs along one or both of the following two dimensions: the mix of customer focus practices that should be adopted; those adverse context characteristics that should be modified. A search for links between the study's findings and existing theory (theory triangulation, Miles and Huberman, pp. 266-267) found relevant links between the results and the concepts of the "service factory" (Chase, 1978; Chase and Garvin, 1989) and "mass customization" (e.g. Pine et al., 1993; Kotha, 1995). These links with theory shed further light on the implications of the study for the implementation of QM. Regarding the mix of practices to adopt, the study suggests that plants exhibiting different manufacturing strategy contexts should use customer focus practices to different extents. The patterns displayed in Table 6 can be used as a starting point (see discussion on the limitations of the study later). In particular, they seem to suggest that it may not be beneficial for a provider of a commodity product to force a high level of use of customer focus practices onto its operations. This finding is consistent with Chase's (1978) recommendations that low contact service operations keep their "technical core" isolated from the customers as much as possible in order to increase efficiency (typically, the positioning of a plant as a provider of a commodity product implies a position analogous to a low contact service operation). In the mass customization literature, it is also recognized that increasing customization may add unnecessary cost and complexity to operations (Gilmore and Pine, 1997) and that mass customization is not appropriate for all markets (Pine et al., 1993; Kotha, 1995).

Concerning the modification of adverse manufacturing strategy context characteristics, this study identified critical context characteristics which appear to strongly affect customer focus practices, namely, the degree of product customization and the degree of service differentiation. Although these characteristics are inherent to a plant's manufacturing strategy context- thus being difficult to change in the short-term-they do provide an extra degree of freedom offering limited opportunities for plants to try to match QM practice to their context. For example, the provider of a commodity product may attempt to change its context by offering some kind of product customization or service differentiation, effectively becoming a bit closer to Chase and Garvin's (1989) concept of the "service factory". The fundamental question is whether this change will be worthwhile under the plant's business environment (e.g. given the intrinsic nature of its markets and the sunk investments already made). An interesting area for future research would be to investigate, from a manufacturing strategy perspective, general courses of action that would make it worthwhile for providers of commodity products to break their context barrier and move to more differentiated manufacturing strategy contexts. In this connection, the strategies for achieving cost-effective customization discussed in the mass customization literature may be a useful starting point (e.g. Gilmore and Pine, 1997; Feitzinger and Lee, 1997).

The hypothesized three configurations of service offering-commodity product, physical product and architecture/service, and manufacturing servicewere also found to have strong resonance in the four service roles that Chase and Garvin (1989) suggest for a factory.

(i) Dispatcher: Supporting customer delivery needs, the distribution function and the after sales needs.

(ii) Showroom: Offering sales support through showing off its products, processes, people and quality commitment.

(iii) Laboratory: Furnishing critical data on processes, such as fast product-build feedback to customers.

(iv) Consultant: Assisting customers in problem solving in areas such as quality improvement, cost reduction and new uses for the customer's products.

In fact, the commodity product configuration may be seen as offering the dispatcher role, with the physical product and architecture/service plant adding the showroom role, and the manufacturing service plant offering all four service roles. Despite this theoretical support, these configurations received only moderate literal replication in the study because the research 
sample encompassed only one plant representing the commodity product and the physical product and architecture/service configurations. Future research should conduct observations in more plants representing these two configurations.

The study's findings can be the object of good generalization to manufacturing plants in discrete goods industries. The replication logic permits analytical generalization, i.e. the generalization of a particular set of results to some broader theory (Yin, 1994). Although the single industry design undoubtedly reduces generalizability, one is still able to make theoreticalas opposed to statistical-inferences about other industries based on this single industry study. In fact, one would expect to observe the same positioning of plants along the manufacturing strategy configuration spectrum in most discrete good industries (e.g. Hayes and Wheelwright, 1979) and one would also expect that the strategic forces shaping QM practice identified under carefully controlled conditions in the electronics industry would also be in play in other industries (although its effects might be felt alongside other industry specific variables). The effects of these strategic forces, although empirically grounded, had their abstraction level raised to general characteristics of manufacturing strategy configurations, beyond the immediate cases. Nevertheless, further research should ascertain whether these results replicate in other industries.

The small sample size did not allow for the testing of whether the uncovered configurations of customer focus practices led to superior overall plant performance. In fact, because of the many factors affecting plant performance (Hackman and Wageman, 1995, p. 320), only a large sample would be likely to reveal any statistically significant effects. Therefore, the study should be complemented with future large scale cross-sectional studies to test the proposed customer focus QM configurations by ascertaining whether plants adopting practice configurations proposed to match their context exhibit superior performance. It would also be important to study the effects of the "improper" use (as suggested by this study's findings) of practices in relation to a plant's context.

At the methodological level, this study pioneers the use of causal network analysis as a tool for theorybuilding in the field of OM. It also shows how case- study research, if properly designed (e.g. tight research controls coupled with careful sample selection), can be adequately used to test propositions, a less frequent application of the case method. Overall, the study may be seen as an example of how case-study research, when conducted with rigor, can yield valid and powerful insights, strengthening its credibility as a research method in the OM field (McCutcheon and Meredith, 1993; Meredith, 1998).

Finally, this study will hopefully contribute to the advancement of the QM philosophy. It has been suggested that the success of early adopters of QM resulted from them having had no easy prescribed solution to turn to and having had to think hard and work it out for themselves (MacDonald, 1993). On the contrary, late followers already had packaged solutions available and there was not the same need for hard thinking, which may have led to a much lower rate of success of QM programs. Part of this hard thinking may have to do with adapting the standard QM practice package to a plant's manufacturing strategy context. It is important to identify the boundaries of applicability of the several QM practices, so that they can be successfully adopted in suitable contexts and not be discredited by failures caused by their forced adoption in unsuitable contexts. This study contributes to this goal by providing implementation guidance for customer focus practices. More contingency studies of this sort are likely to be a promising avenue for taking the maturing QM field further forward.

\section{Appendix A}

Template for the displays used for the reduction of contextual data.

CTX: Degree of product customization (CTM), rate of new product introduction (RNPI), typology of dominant process (PROC), production volume (VOL), internal run sizes (IRS) and internal item variety (IIV). Variable CTM was measured for a plant's main product line. Variables PROC, VOL, IRS, and IIV were measured in the dominant process of a plant, defined as comprising the PCB assembly lines used to produce the main product line. The items associated with these variables were developed based on an in-depth study of the PCB assembly process and discussions with persons knowledgeable about this manufacturing process. 


\begin{tabular}{ll}
\hline CTX & Measurement items/characterization of the context variable \\
\hline CTM & $\begin{array}{l}\text { Nature of customization (extent to which customers } \\
\text { influence the product that is provided). Emphasis is } \\
\text { on the consequences of customization to manufacturing. }\end{array}$ \\
RNPI & (1) Instability of product designs, both across new product \\
introductions (1(L)-3(H) rating) and during a product's life \\
cycle (1(L)-3(H) rating). Overall item rating is determined by \\
the application of rule R2 to these two individual ratings. \\
(2) Consequences of new product introductions to \\
manufacturing. Application of rule R1.1 to the ratio "internal \\
item variety rating (see later)/average product life cycle rating \\
(applying rule R1.1.)" to yield a 1(L)-3(H) rating. The more \\
products a plant produces and the shorter are their life cycles, \\
the more manufacturing is subject to new product \\
introductions.
\end{tabular}

PROC Layout (line vs. functional), product routes (fixed vs. variable). "L" represents the extreme "line layout, fixed routes" (line process), $\mathrm{H}$ the extreme "functional layout, variable routes" (jobbing process), and $\mathrm{M}$ a high volume batch process.

VOL Total number of PCBs assembled in 1 year, adjusted for the number of physical PCB assembly lines in the dominant process

IRS Average production batch size, as "experienced" by the process $=($ down time for a set-up)/(average work content of a batch), (L-H, reverse coded), where: average work content of a batch $=$ average total number of components to be placed $=$ average number of components per board $\times$ average batch size The down time for a set-up is used as a proxy for the complexity of the changeover. The work content of a batch is used as a proxy for the time it takes for the batch to be processed. The longer the down time for a set-up relative to the batch processing duration, the shorter is the size of the run, "as experienced by the process". Many short batches of very similar products, requiring very quick set-ups, could be considered as a long run.

IIV (1) Number of unique board types (different part numbers) (L-H, rule R1.1).

(2) Number of different board sizes (L-H, rule R1.1).

(3) Average number of components per board: this is a measure of the size of the differences between individual boards. More components increase the scope for differences between individual boards (e.g. more complex set-ups of placement machines, different thermal masses, wider spreads of component locations on the board, etc.) (L-H, rule R1.1).

$\mathrm{L}-\mathrm{H}$, applying rule $\mathrm{R} 2$ to the two individual items

L-H, rule R1.2

L-H, rule R1.1

L-H, rule R1.1 (L-short runs; H-long runs)

$\mathrm{L}-\mathrm{H}$, applying rule $\mathrm{R} 2$ to the five individual items 


Appendix A (Continued)
\begin{tabular}{lll} 
CTX & Measurement items/characterization of the context variable \\
\hline
\end{tabular}

(4) Average number of different types of components per

board: same as previous (L-H, rule R1.1).

(5) Difficulty of the set-up operations: this is a combination of

the sheer item variety and the plant's ability and resources put

into simplifying set-ups. This item captures variety as

"experienced" by the process (L-H, rule R1.2).

${ }^{a}(\mathrm{~L}-\mathrm{H})$ : indicates that the measurement item is classified into one of three levels: low (1); medium (2); and high (3) by the application of an appropriate rule to the observations made across all cases.

\section{References}

Ahire, S., 1996. TQM age versus quality: an empirical investigation. Production and Inventory Management Journal First Quarter, 18-23.

Ahire, S., Golhar, D., Waller, M., 1996. Development and validation of TQM implementation constructs. Decision Sciences 27 (1), 23-56.

Benson, G., Saraph, J., Schroeder, R., 1991. The effects of organizational context on quality management: an empirical investigation. Management Science 37 (9), 1107-1124.

Chase, R., 1978. Where does the customer fit in a service operation? Harvard Business Review November-December, 137-142.

Chase, R., Garvin, D., 1989. The service factory, Harvard Business Review July-August, 61-69.

Conover, W., 1999. Practical Nonparametric Statistics, 3rd Edition. Wiley, New York.

Corrigan, J., 1994. Is ISO 9000 the path to TQM? Quality Progress May, 33-36.

Cuzick, J., 1985. A Wilcoxon-type test for trend. Statistics in Medicine 4, 87-90.

Dale, B., Lascelles, D., 1997. Total quality management adoption: revisiting the levels. The TQM Magazine 9 (6), 418-428.

Das, A., Handfield, R., Calantone, R., Ghosh, S., 2000. A contingent view of quality management-the impact of international competition on quality. Decision Sciences 31 (3), 649-690.

Dean, J., Bowen, D., 1994. Managing theory and total quality: improving research and practice through theory development. Academy of Management Review 19 (3), 392-418.

Dow, D., Samson, D., Ford, S., 1999. Exploding the myth: do all quality management practices contribute to superior quality performance? Production and Operations Management 8 (1), $1-27$.

Eisenhardt, K., 1989. Building theories from case-study research. Academy of Management Review 14 (4), 532-550.

Feitzinger, E., Lee, H., 1997. Mass customization at HewlettPackard: the power of postponement. Harvard Business Review January-February, 116-121.
Flynn, B., Schroeder, R., Sakakibara, S., 1995. The impact of quality management practices on performance and competitive advantage. Decision Sciences 26 (5), 659-692.

Gilmore, H., Pine II, B., 1997. The four faces of mass customization. Harvard Business Review January-February, 91-101.

Hackman, J., Wageman, R., 1995. Total quality management: empirical, conceptual, and practical issues. Administrative Science Quarterly 40, 309-342.

Harari, O., 1993. Ten reasons why TQM doesn't work. Management Review 82 (1), 33-38.

Harrigan, K., 1983. Research methodologies for contingency approaches to business strategy. Academy of Management Review 8 (3), 398-405.

Hayes, R., Wheelwright, S., 1979. Link manufacturing process and product life cycles. Harvard Business Review January-February, 133-140.

Hendricks, K., Singhal, V., 2001. Firm characteristics, total quality management, and financial performance. Journal of Operations Management 19, 269-285.

Hill, T., 1985. Manufacturing Strategy: The Strategic Management of the Manufacturing Function. Macmillan, London.

Kekre, S., Murthi, B., Srinivasan, K., 1995. Operating decisions, supplier availability and quality: an empirical study. Journal of Operations Management 12 (3), 387-396.

Kotha, S., 1995. Mass customization: implementing the emerging paradigm for competitive advantage. Strategic Management Journal 16, 21-42.

Lawler, E., 1994. Total quality management and employee involvement: are they compatible? Academy of Management Executive 8 (1), 68-76.

Maani, K., 1989. Productivity and profitability through qualitymyth and reality. International Journal of Quality and Reliability Management 6 (3), 11-23.

MacDonald, J., 1993. TQM: does it always work? TQM Practitioner Series. Technical Communications Publishing Ltd., London.

Madu, C., Kuei, C., Lin, C., 1995. A comparative analysis of quality practice in manufacturing firms in the US and Taiwan. Decision Sciences 26 (5), 621-636.

McCutcheon, D., Meredith, J., 1993. Conducting case-study research in operations management. Journal of Operations Management 11, 239-256. 
Meredith, J., 1998. Building operations management theory through case and field research. Journal of Operations Management 16, 441-454.

Miles, M., Huberman, A., 1994. Qualitative Data Analysis: An Expanded Sourcebook, 2nd Edition. Sage Publications, Beverly Hills, CA.

Miller, J., Roth, A., 1994. A taxonomy of manufacturing strategies. Management Science 40 (3), 285-304.

Papa, F., 1993. Linkage of old and new. Management Review $82(1), 63$.

Pine II, B., Victor D., Boynton, A., 1993. Making mass customization work. Harvard Business Review SeptemberOctober, 108-119.

Powell, T., 1995. TQM as competitive advantage: a review and empirical study. Strategic Management Journal 16 (1), 15-37.

Reed, R., Lemak, D., Montgomery, J., 1996. Beyond process: TQM content and firm performance. Academy of Management Review 21 (1), 173-202.

Samson, D., Terziovski, M., 1999. The relationship between total quality management practices and operational performance. Journal of Operations Management 17 (4), 393-409.

Sitkin, S., Sutcliffe, K., Schroeder, R., 1994. Distinguishing control from learning in total quality management: a contingency perspective. Academy of Management Review 19 (3), 537-564.
Sousa, R., 2000. Quality management practice: universal or context dependent? An empirical investigation, Unpublished Ph.D. thesis. London Business School, London.

Sousa, R., Voss, C., 2001. Quality management: universal or context-dependent? Production and Operations Management Journal 10 (4), 383-404.

Sousa, R., Voss, C., 2002. Quality management re-visited: a reflective review and agenda for future research. Journal of Operations Management 20 (1), 91-109.

Stobaugh, R., Telesio, P., 1983. Match manufacturing policies and product strategy. Harvard Business Review March-April, 113-120.

Victor, B., Boynton, A., Stephens-Jahng, T., 2000. The effective design of work under total quality management. Organization Science 11 (1), 102-117.

Ward, P., Bickford, D., Leong, G., 1996. Configurations of manufacturing strategy, business strategy, environment, and structure. Journal of Management 22 (4), 597-626.

Woodward, J., 1965. Industrial Organization: Theory and Practice. Oxford University Press, London.

Yin, R., 1994. Case-study research: design and methods. In: Applied Social Research Methods Series. SAGE Publications, 2nd Edition. Beverly Hills, CA. 